\title{
Ethics of Case Studies Based on Human Dignity
}

ISSN: 2639-0531

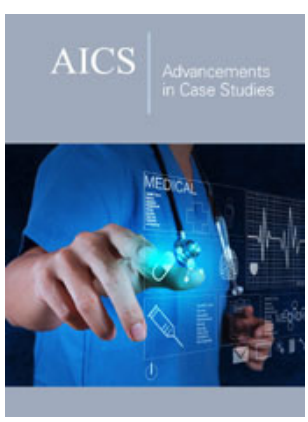

*Corresponding author: Michael Anjello J, Tamil Nadu State Council for Science and Technology, India

Submission: 海 August 01, 2019

Published: 侮 August 20, 2019

Volume 2 - Issue 1

How to cite this article: Michael Anjello J. Ethics of Case Studies Based on Human Dignity. Adv Case Stud.2(1). AICS.000527.2019.

DOI: 10.31031/AICS.2019.02.000527

Copyright@ Michael Anjello J, This article is distributed under the terms of the Creative Commons Attribution 4.0 International License, which permits unrestricted use and redistribution provided that the original author and source are credited.
Michael Anjello J*

Tamil Nadu State Council for Science and Technology, India

\section{Introduction}

Ethics plays a major role in upholding Human Dignity in any field of research and development. Case studies are not exceptional to it. Most of the researchers follow the Belmont Report on guiding principles in Research Ethics with reference to Justice, Beneficence and Autonomy. Ethics Committees were established Internationally (IRB) and every country in every field of human welfare have their own ethical committees. Most of us will be familiar with Medical Ethics Committees or Clinical Ethics Committees and their functions.

Case study can be redefined as the scientific process of exploring an individual, group, organization or event in their primary, secondary or tertiary settings. It depends on the existence of a nano-micro-macro link in characteristics that are to be studied. It is one of the forms of cross-level inference.

Different types of case studies are given below:

\section{Illustrative case studies}

These are primarily descriptive studies. They typically utilize one or two instances of an event to show what a situation is like. Illustrative case studies serve primarily to make the unfamiliar familiar and to give readers a common language about the topic in question.

\section{Exploratory (or pilot) case studies}

These are condensed case studies performed before implementing a large-scale investigation. Their basic function is to help identify questions and select types of measurement prior to the main investigation. The primary pitfall of this type of study is that initial findings may seem convincing enough to be released prematurely as conclusions.

\section{Cumulative case studies}

These serve to aggregate information from several sites collected at different times. The idea behind these studies is the collection of past studies will allow for greater generalization without additional cost or time being expended on new, possibly repetitive studies [1].

\section{Critical instance case studies}

These examine one or more sites for either the purpose of examining a situation of unique interest with little to no interest in generalizability, or to call into question or challenge a highly generalized or universal assertion. This method is useful for answering cause and effect questions.

In any form of case study, it should be borne in mind that human dignity is not sacrificed. This may trigger a conflict in some of us. How case studies about a criminal can be justified with regard to human dignity? In this regard it is better to RENAME the criminal's original name and case study can be continued. Here we emphasize that being born as a human the person has autonomy to live and enjoy the benefits from the society adhering to the laws and regulations of the respective countries [2]. It is not the natural growth of the person that makes him a criminal. There may be circumstances beyond the control of the person's emotions which makes him an evil doer. But we have to ignore them as they are very less in number. If case studies of these types of persons are studied as lessons by children and adolescents there may be a tendency to imitate the hero in the case study. The present movies 
and the media could not be easily case studied objectively because of the impracticality of certain titles, themes, characters, actions, fights etc.

The researcher who intends to study a case and prepare the report should ask and clarify the following questions and then proceed:

A. Is this case study worth of spending time?

B. What will be the benefit for the self?

C. How will the society look at the case study report?

D. Does the case study obstruct the autonomy of the persons who will be the subjects in the case study?

E. Can another researcher extend the case study and be benefitted?

F. Is it easier to construct and validate the tools for cases studies in a more scientific way?

G. Is there any chance of the subject(s) withdrawing during the midway of the research study?

H. Will there be any approximations to be made? Approximations destroy the objectivity of the study. Hence in any case study one should not make any approximations and it should be a true and exact data.

I. Has informed consent been obtained from the subject, if it is regulated by governmental norms and regulations?

J. Are there any chances to make assumptions during the course of the study? If assumptions are made then the case study will lack its originality and becomes a biography.
K. Does the case study depend upon funding or any other support to complete the work?

L. Ethical principles are concepts that underlie the specific guidelines that are spelt out in code of ethics. Codes of ethics attempt to, but realistically cannot address all possible ethical dilemmas involved in case study during the course of work. Ethical principles contain the essential values or core concepts that can guide the resolution of ethical dilemmas.

The most important characteristic of a scientist who carries out case study is honesty as the study is taken as a reference by the followers all over the world. Hence more emphasis should be given to see that the Dimensions of Human Dignity in any form of case studies are not degraded for the welfare of the future generations.

\section{Conclusion}

Indeed, the case study is probably best understood as an ideal type rather than a method with hard-and-fast rules. Yet the fact that the case study is fuzzy around the edges does not mean that it is lacking in distinctive characteristics. When considered as an ideal type the case study research design, like all research designs, exhibits characteristic strengths and weaknesses relative to its across-unit cousin.

\section{References}

1. Yin Robert K (2017) Case study research and applications: Design and methods. Sage publications, USA.

2. Gerring J (2004) What is a case study and what is it good for? American Political Science Review 98(2): 341-354.

For possible submissions Click below: 